\title{
Effective Schools do Exist: Low Income Children's Academic Performance in Chile
}

\author{
Francisco Henríquez \\ Universidad Católica of Valparaíso and Ministry of Education \\ Bernardo Lara \\ School of Education, Stanford University
}

Alejandra Mizala*

Center for Applied Economics, Department of Industrial Engineering, University of Chile

Andrea Repetto

School of Government, Universidad Adolfo Ibáñez

This version

April, 2011

\footnotetext{
* Acknowledgements: We thank Lily Ariztía and Bernardita Muñoz who provided valuable information about the SIP schools, as well as comments and suggestions. We also thank Magdalena Álvarez and Javiera Martínez for excellent assistance. We are grateful to the SIMCE office at Chile's Ministry of Education for the data. Funding from Fondecyt (\#1070316) and PIA-CONICYT Project CIE-05 is gratefully acknowledged.
}

Corresponding author: E-mail: amizala@dii.uchile.cl. 


\begin{abstract}
The aim of this paper is twofold. First, we show that despite students' disadvantaged backgrounds and despite not having more financial resources than similar schools, there are schools in Chile that serve low income students and that obtain superior academic outcomes. Second, we present qualitative evidence to identify school and classroom processes that might explain these good results. Specifically, we analyze a network of Chilean private voucher schools called Sociedad de Instrucción Primaria (SIP). In the econometric analysis we use a number of propensity score based estimation methods, to find that SIP students' achievement is not due to observables or selection on measured variables. We also perform a number of interviews to SIP schools and other neighboring schools. Our qualitative analysis suggests that having children's learning as a central and permanent goal, an aim that is shared and that drives the community's efforts, seems to best summarize what makes SIP schools special.
\end{abstract}

Keywords: Educational quality, effective schools, school effect, propensity score. 


\section{Introduction}

Educational researchers and policymakers have long struggled in their efforts to understand whether schools matter and whether there are policies that improve achievement. A large body of literature provides mixed results on the role of school resources on student performance. ${ }^{1}$

At the same time, educational systems display great variation in the distribution of achievement as measured by test scores, dropout rates and college attendance (OECD, 2009). This enormous diversity is correlated with but not fully accounted for by students' family background and experiences. Chile's educational system is no exception as it is also characterized by a large heterogeneity in results that is not completely captured by students' socio-economic characteristics (Mizala and Romaguera, 2005).

In the early 1980s sweeping reforms were introduced to improve coverage and quality: the public sector school system was decentralized and school management was delegated to municipal authorities. The reform also paved the way for the private sector to enter the market as a provider of education by introducing a voucher-type demand subsidy to finance municipal/public and privately run voucher schools. The voucher, which is paid directly to schools on a per-student basis, is intended to cover running costs and generate competition between schools to attract and retain students, thus promoting more efficient and better quality education services. Three decades after, schools with stagnant scores still co-exist with schools that show continuous progress.

\footnotetext{
${ }^{1}$ Literature reviews include Hanushek $(1989,1997)$ for developed countries and Fuller (1990), Fuller and Clarke (1994) and Hanushek (1995) for developing countries.
} 
This paper adds evidence on the educational strategies that are effective for students from disadvantaged backgrounds. Based upon the experience of children attending schools that belong to the Sociedad de Instrucción Primaria (SIP), a non-for profit organization that serves low income students in Santiago, we provide both statistical and qualitative evidence that it is possible to educate low income children and consistently produce outstanding results.

Students at these schools stand out because of their systematic superior performance in national standardized SIMCE tests (Educational Quality Measurement System). Despite their students' disadvantaged family background and despite not having more financial resources than similar schools, SIP schools obtain test scores that are up to one standard deviation higher than those obtained by public schools, and up to 70 percent of one standard deviation higher than private voucher schools in Santiago. Furthermore, the performance of SIP schools is very similar to that of private non-voucher schools that typically serve the most elite families in Chile. SIP students also show a lower level of heterogeneity in results. In other words, SIP's education seems a cost effective way of improving school quality.

The main goal of this paper is to shed light on the factors that contribute to a better education for low-income students. The lessons of this analysis can help improve the performance in schools with poor achievement.

We first we analyze whether the superior performance of SIP students can be explained by observable factors or selection. Using propensity score estimation methods we find that after controlling for observables and selection, SIP students perform much better than 
students at private voucher and public schools with differences up to 0.9 standard deviations. These students perform even better than those attending private non voucher schools.

We then look further into understanding the unmeasured variables that explain SIP's performance by conducting interviews with SIP's principals and with the principals of schools that compete with them. For each SIP school and within the same municipality, we chose similar schools. Our interviews reveal a number of relevant differences across schools. Perhaps the most striking one is that SIP schools have had children's learning as their primary and permanent goal, an aim that is shared and that drives the community's efforts.

The remainder of the paper is organized as follows: Section II introduces SIP schools and analyzes the robustness of its superior performance to controlling for observables and for selection on measured variables. Section III describes the results of our interviews. Section IV concludes.

\section{SIP schools and their relative performance}

SIP schools are private voucher schools. Out of a total of 17 schools, 15 serve children at the primary level. Our study is based on the performance of children at these primary level schools.

The direction of the schools is under central management which delineates the general aims, leaving each school enough autonomy to attain the goals in different ways. The 
Pedagogical Department defines standards and the progress expected from every school. It also monitors performance, evaluates achievement and organizes remedial measures whenever goals are not met. It is also in charge of ensuring that families participate in the educational process.

SIP schools are mainly financed by the state voucher, which represents $80 \%$ of all revenue. The remainder comes from fees charged to parents and donations, typically targeted to specific projects, like libraries and infrastructure.

Table 1 summarizes the superior results that SIP students obtained in the 2002 SIMCE, a math and language national standardized test taken by all $4^{\text {th }}$ graders in Chile ${ }^{2}$. Table 2 summarizes the main characteristics of schools, students and their families by school type. Students at public schools belong to less advantaged households, with lower parental income and education and with access to fewer educational resources at home and fewer financial resources at school. Students attending SIP schools seem quite similar to those attending other private voucher schools in a number of relevant characteristics such as household income and maternal education. Nevertheless, they are more likely to have a computer at home and to own a larger number of books, differences that might capture parental motivation. Teachers at SIP schools have more years of experience. Table 2 also shows the large resource advantage of children attending private non-voucher schools. We do not have information on the amount of resources per child at these elite schools, but tuition charges can reach up to 10 times the voucher.

\footnotetext{
${ }^{2}$ Our econometric results are based on the 2002 SIMCE test. However, SIP students have systematically
} excelled in all SIMCE tests. 
The goal of this section is to evaluate the treatment effect of attending a SIP school on students' performance. The main challenge is to address selection bias (SIP students may have unobserved characteristics that are correlated with academic achievement), since parents are free to choose a school for their children, and at the same time, private schools are free to choose the students they enroll. We use propensity score based techniques to evaluate the effect of treatment on achievement. We perform comparisons across treatment and control groups, with three controls group each defined by a different school type school.

We implement three estimators of the effect of SIP education: the one-to-one estimator with replacement, propensity score weighting and propensity score weighted regression. ${ }^{3}$ The second method weights the observations balancing the sample between treated and nontreated individuals based on the probability of treatment (Imbens and Wooldridge, 2009). We use the inverse probability weighting (IPW) estimator proposed by Hirano, Imbens and Ridder (2003). The third method, the double-robust estimator (DR), allows us to directly account for the correlation between covariates and outcomes (Robins and Rotnizky (1995), Robins et al (1995), and Robins and Ritov (1997)). ${ }^{4}$ Our implementation of the IPW and DR estimators follows Emsley et al. (2008).

\footnotetext{
${ }^{3}$ It is worth emphasizing that the usual assumptions needed for consistency may not hold. For instance, SIP schools may admit students on the basis of unobserved measures or the most motivated parents -in unmeasured ways - may enroll their children in SIP schools. We would then overestimate the true effect of SIP education.

${ }^{4}$ Further details on this method can be found in Imbens (2004) and Imbens and Wooldridge (2009).
} 
The first stage of our strategy is the estimation of the propensity score using all observations $^{5}$. The results -available upon request—-suggest that most variables are correlated with school choice, in particular family income, maternal education, household size, age, having attended pre-school, educational resources at home, school financial resources and the teachers/pupil ratio.

The second stage of our model estimates the effect of attending a SIP school. The results are summarized in Table 3. The first panel compares the scores of students enrolled at a SIP school relative to similar students enrolled at a public school. The differences are very large and always statistically significant, ranging from 0.48 to 0.57 standard deviations in the language test, and from 0.74 to 0.87 standard deviations in the math test. When compared to similar students at other private voucher schools, the effect of SIP education is again very large, never lower than 0.25 standard deviations. Relative to private non voucher schools the effect is also large, ranging from 0.27 to 0.52 standard deviations, even considering these schools are not a realistic option for most students.

These results indicate that SIP schools are able to provide high quality education to low income students who outperform similar students attending any other type of school. Although the point estimates vary from method to method, they all suggest that the effect is large and economically relevant. Given their financial resources, SIP's methods seem a

\footnotetext{
${ }^{5}$ In addition to the usual strategy of limiting the sample to the common support, we follow Crump et al (2008) in selecting the group with overlap that minimizes the asymptotic variance of the efficient estimator of the average treatment effect. This trimming is one way of solving the lack of overlap in the covariate distributions due to a limited number of observations. This problem can lead to imprecise estimates that are sensitive to the specification chosen. In practice, we discard observations with propensity scores less than 0.1 away from zero and one.
} 
cost-effective way of improving the quality of education among low income students. Just like the best educational systems described by Barber and Mourshed (2007), SIP methods are able to compensate for student background disadvantages.

\section{A qualitative assessment of SIP schools}

Previous research on factors affecting the effectiveness of schools attending low-income students have found that variables correlated with high achievement are not easy to measure; thus, a qualitative analysis is needed. With this in mind, we performed interviews with SIP schools' principals and with principals of schools that enroll similar students in the neighborhoods. We interviewed one "neighbor" school for each SIP school. To choose the schools to interview, we generated a "similarity index" evaluated for each school in the neighborhood served by a SIP school on the basis of a vulnerability index ${ }^{6}$, the average family income at the school, maternal education, enrollment and fees. The guideline we prepared for the interviews is based on the effective schools literature. It included questions on teaching methods, directors' goals and activities, teachers' and students' characteristics, and general school practices. ${ }^{7}$

From the analysis of the interviews it is possible to sketch some features that may help understand better SIP's academic results. These are summarized below.

\footnotetext{
${ }^{6}$ The National School Support and Scholarship Board constructs this vulnerability index at the school level to target meal subsidies.

7 The guideline, method, schools' characteristics and detailed results for this section can be found in Henríquez et al. (2009).
} 


\section{Selection of directors, and teachers' recruitment and dismissal: Most of SIP's}

principals and the personnel directly below them have been designated by central authorities through a competitive process. At SIP most principals regard themselves as autonomous in hiring and firing teachers, although some note that these must be consistent with SIP criteria.

Outside SIP, only occasionally the principal reports having competed for the post. Also, the directors do not have the power to choose the members of the directive team. Contrary to principals at SIP, they cannot appoint or dismiss teachers. It's either the municipality or the owner who takes the decisions.

Goals: At SIP schools, all principals claim to have students' academic performance as the primary goal. Schools outside SIP have heterogeneous missions. According to some principals, their aim is to make children believe in themselves and to give them the skills and tools they need to overcome poverty. Others state that their goal is to make children feel protected and taken care of within the school. One director states that teaching values - fraternity, respect and laboriousness- is their goal. Another one emphasizes extracurricular activities, allowing children to excel in sports, music and other areas.

Tasks and autonomy assigned to directors: SIP principals define their position as being characterized by one mission: student achievement. Standards are clearly defined; the team works with the Pedagogical Department to set these standards. Work is planned jointly and guided by results. On the contrary, non-SIP principals devote most of their time to meetings held mostly outside the school, to filling out reports and surveys mainly sent out by the Ministry, and to overall supervision. 
Teaching methods: SIP schools rely on monthly counseling by the Pedagogical

Department which is principally delivered as methodological instructions. The schools plan their objectives, content and activities, and they progress according to the fulfillment of these objectives. Goals are common across schools and clearly established. Discipline is also considered as key to teaching. The educational process involves parents who are periodically informed about performance. Most principals outside SIP are able to identify a specific teaching methodology, but in sharp contrast to SIP's approach, many state the teachers are free to teach the way they feel most comfortable. Many have adopted the guidelines created by the Ministry of Education.

Teachers' evaluation and pay: At SIP teachers are constantly evaluated on the basis of a self-evaluation process, 'formative evaluations' through which teachers frequently discuss their activities with the principal, and class observation. The best evaluated teachers participate in these observations in order to share the best practices. The evaluations provide feedback to teachers and the administration, and are also used for the definition of bonuses, training and dismissal.

All "neighbor" schools evaluate their teachers, but not all of them follow a formal procedure. Some rely on the ministerial or municipal evaluations, or on procedures adopted from external institutions. In occasions, evaluations are subjective, based on the director's observations and given out to the teachers through informal conversations.

At SIP teachers' pay consists of a basic salary plus an amount for meeting goals. In almost all interviewed schools outside SIP, teachers receive a fixed income equal to the minimum scheme set by the Ministry. Some directors are against monetary incentives, because they 
may generate competition and tension within the school. In some schools, however, teachers are eligible to receive a bonus related to their effort and performance.

Evaluation of students: SIP schools undertake systematic evaluations of their students with standardized tests taken twice a year. The results are shared with teachers who are expected to align the focus of their lectures to the needs of students. Subject advisors provide extra support when needed. Test results are also used to identify areas which students that lag behind need to strengthen, and for teachers to ask parents for extra involvement. The information is further used to identify advanced students who can benefit from special workshops.

Non SIP schools typically use no systematic student evaluation other than the tests that teachers routinely use to grade achievement. Thus, performance comparisons across classrooms and over time cannot be made. In two cases, however, external standardized tests are administered. Schools also claim that they lack resources to level children that lag behind. In one school, lagging students are evaluated using a lower standard.

\section{Assessment}

Low income children can achieve good academic results as SIP's experience suggests. In order to better understand the underlying unobserved characteristics of SIP's education, we gathered qualitative information. Although our interviews do not pinpoint one single key characteristic, we were able to identify a number of relevant aspects: method of selection of directors and teachers; orientation towards student learning; systematic use of teachers and 
students' evaluation and actions taken based on the information gathered; a clear and shared methodology; sharing of the best practices; incentive pay, and resources devoted to leveling children that lag behind.

Some of these strategies have been described in the literature as relevant for success. For instance, Barber and Mourshed (2007) point at the quality of teachers, informed through evaluation processes. Also, Välijärvi et al (2002 and 2007) suggest that the leveling of lagging students is a strategy that helps all children in the classroom.

It is worth noting that some of the low performing schools do implement some of these strategies. This suggests that there are aspects that matter but that are not fully captured by our interviews. These may include the intensity and perseverance in the application of these strategies, their coherence and how strongly are they shared by teachers, staff, parents and children. Still, having children's learning as a central and shared goal --a goal that for a long period of time has driven the community's efforts-- seems to best summarize what makes SIP special.

Alternatively, SIP's results may be driven by the fact that it is a network of schools and that many of their practices are too expensive for stand-alone schools. Nonetheless, public schools also constitute a network under a central management at the municipal level that could take advantage of economies of scale.

The main result of this paper, though, is that schools that successfully serve low income students do exist. This success does not hinge on selection or a better access to resources, but on a number of strategies that if systematically applied, might improve the performance of underprivileged students. 


\section{References}

Barber, M. and Mourshed, M. (2007). "How the World's Best-Performing School Systems Come-Out on Top", McKinsey \& Company.

Crump, R. K., Hotz, V. J., Imbens, G. W. and Mitnik. O. A. (2009). "Dealing with Limited Overlap in Estimation of Average Treatment Effects" Biometrika 96:187-199.

Emsley, E., M. Luna, A. Pickles and G. Dunn (2008). "Implementing double-robust estimators of causal effects," Stata Journal, Vol. 8(3), pages 334-353.

Fuller, B. (1990). "Raising school quality in developing countries: What investment boosts learning? World Bank Discussion Paper Nº76, Washington DC, World Bank.

Fuller, B. and Clarke, P. (1994) "Raising schools effects while ignoring culture, local conditions and the influence of classroom tools, rules and pedagogy", Review of Educational Research, 64(1), 119-157.

Hanushek, E. (1989). "The impact of differential expenditures on school performance". Educational Researcher 18(4), 45-51.

Hanushek, E. (1995). "Interpreting recent research on schooling in developing countries" The World Bank Research Observer 10(2), 227-246.

Hanushek, E. (1997). "Assessing the effects of school resources on student performance: An update" Educational Evaluation and Policy Analysis 19(2), 141-164.

Henríquez, F., Lara, B., Mizala, A. and A.Repetto (2009), "Effective Schools do Exist: Low Income Children's Academic Performance in Chile," Universidad Adolfo Ibáñez, School of Government, Working Paper 3.

Hirano, K., Imbens, G. and G. Ridder (2003). "Efficient Estimation of Average Treatment Effects Using the Estimated Propensity Score," Econometrica, Vol. 71(4), 11611189.

Imbens, G.W. (2004). "Nonparametric estimation of average treatment effects under exogeneity: a review." Review of Economics and Statistics, Vol 86(1): 4-29.

Imbens, G.W. and J. Wooldridge (2009), "Recent Developments in the Econometrics of Program Evaluation" Journal of Economic Literature, 47(1): 5-86.

Mizala, A. and Romaguera, P. (2005). "Calidad de la Educación Chilena: el Desafío de la Próxima Década”, en P.Meller (ed.) La Paradoja Aparente, Taurus, Santiago, Chile.

OECD (2009). Education at a Glace 2009.

Robins, J. M., and Y. Ritov (1997). "Toward a Curse of Dimensionality Appropriate (CODA) Asymptotic Theory for Semi-parametric Models", Statistics in Medicine, Vol. 16(3): 285-319. 
Robins, J. M., and A. Rotnitzky (1995). "Semiparametric Efficiency in Multivariate Regression Models with Missing Data." Journal of the American Statistical Association, Vol. 90(429): 122-29.

Robins, J. M., A. Rotnitzky, and L. P. Zhao (1995). "Analysis of Semiparametric Regression Models for Repeated Outcomes in the Presence of Missing Data." Journal of the American Statistical Association, Vol. 90(429): 106-21.

Välijärvi, J., Kupari, P., Linnakylä, P., Reinikainen and Arffman, I. (2002) The Finnish success in PISA, and some reasons behind it. PISA 2000. Institute for Educational Research, University of Jyväskylä.

Välijärvi, J., Kupari, P., Linnakylä, P., Reinikainen, P., Sulkunen, S., Törnoos, J. and Arffman, I. (2007) The Finnish success in PISA, and some reasons behind it. PISA 2003. Institute for Educational Research, University of Jyväskylä. 
Table 1. Average $20024^{\text {th }}$ grade SIMCE Scores by School Type Metropolitan Region of Santiago, Urban Areas

\begin{tabular}{lcccc}
\hline & \multicolumn{2}{c}{ Language } & \multicolumn{2}{c}{ Math } \\
\hline & Mean & SD & Mean & SD \\
Public & 239.0 & 51.5 & 235.5 & 52.0 \\
Private voucher schools & 258.8 & 52.1 & 253.6 & 51.8 \\
Private non-voucher & & & & \\
schools & 297.2 & 42.8 & 295.2 & 44.4 \\
SIP schools & 282.9 & 42.1 & 290.6 & 43.5 \\
All & 251.4 & 53.7 & 247.4 & 54.0 \\
\hline
\end{tabular}

Source: SIMCE 2002 database. 
Table 2. Descriptive Statistics of Students and Schools by School Type Means and Standard Deviations

\begin{tabular}{|c|c|c|c|c|}
\hline & SIP & Public & Private voucher & Private non voucher \\
\hline \multirow[t]{2}{*}{ Number of schools in student's neighborhood } & 49.27 & 46.29 & 59.08 & 45.72 \\
\hline & $(19.49)$ & $(28.92)$ & $(31.87)$ & $(25.36)$ \\
\hline \multirow[t]{2}{*}{ Mother's education in years } & 12.33 & 9.80 & 11.83 & 15.36 \\
\hline & $(2.39)$ & $(3.17)$ & $(2.93)$ & $(2.34)$ \\
\hline \multirow{2}{*}{ Family income (thousands chilean pesos) } & 266.84 & 163.13 & 270.12 & 1248.73 \\
\hline & $(197.09)$ & $(162.91)$ & $(232.93)$ & $(607.05)$ \\
\hline \multirow[t]{2}{*}{ Number of people at home } & 4.78 & 5.08 & 4.82 & 5.05 \\
\hline & $(1.62)$ & $(1.87)$ & $(1.59)$ & $(1.58)$ \\
\hline \multirow[t]{2}{*}{ More than 10 people at home } & 0.02 & 0.03 & 0.02 & 0.01 \\
\hline & $(0.13)$ & $(0.18)$ & $(0.12)$ & $(0.11)$ \\
\hline \multirow[t]{2}{*}{ Attended preschool } & 0.99 & 0.96 & 0.98 & 1.00 \\
\hline & $(0.12)$ & $(0.20)$ & $(0.14)$ & $(0.07)$ \\
\hline \multirow[t]{2}{*}{ Age } & 9.54 & 9.67 & 9.56 & 9.71 \\
\hline & $(0.52)$ & $(0.71)$ & $(0.59)$ & $(0.54)$ \\
\hline \multirow[t]{2}{*}{ Female } & 0.46 & 0.48 & 0.49 & 0.50 \\
\hline & $(0.50)$ & $(0.50)$ & $(0.50)$ & $(0.50)$ \\
\hline \multirow[t]{2}{*}{ Student has a computer at home } & 0.46 & 0.15 & 0.36 & 0.85 \\
\hline & $(0.50)$ & $(0.35)$ & $(0.48)$ & $(0.35)$ \\
\hline \multirow[t]{2}{*}{ Number of books at home } & 61.25 & 34.59 & 53.72 & 110.77 \\
\hline & $(61.70)$ & $(48.47)$ & $(58.65)$ & $(78.16)$ \\
\hline \multirow{2}{*}{ School's enrollment 2002} & 1176.83 & 1053.14 & 1343.30 & 1026.86 \\
\hline & $(220.35)$ & $(728.29)$ & $(1286.75)$ & $(669.57)$ \\
\hline \multirow[t]{2}{*}{ School's resources per student $(\mathrm{Ch} \$)$} & 27591.87 & 9679.59 & 31324.37 & \\
\hline & $(2567.65)$ & $(16068.08)$ & (7978.73) & \\
\hline \multirow[t]{2}{*}{ Teachers per pupil ratio } & 0.03 & 0.04 & 0.03 & 0.06 \\
\hline & $(0.00)$ & $(0.01)$ & $(0.02)$ & $(0.03)$ \\
\hline \multirow[t]{2}{*}{ Teacher's experience in years } & 23.78 & 22.78 & 16.64 & 17.46 \\
\hline & $(7.75)$ & $(9.98)$ & $(10.03)$ & $(9.21)$ \\
\hline Number of observations & 849.00 & 19281.00 & 22921.00 & 6806.00 \\
\hline
\end{tabular}

Source: SIMCE 2002 database. 
Table 3. The Estimated Effect of SIP Education. $4^{\text {th }}$ grade SIMCE scores, 2002

\begin{tabular}{|l|c|c|c|c|}
\hline & \multicolumn{2}{|c|}{ Language } & \multicolumn{2}{c|}{ Math } \\
\hline SIP vs. Public Schools & & & \\
\hline OLS & 27.942 & $* * *$ & 41.8593 & $* * *$ \\
\hline & $(3.203)$ & & $(3.4033)$ & \\
\hline Matching & 30.5166 & $* * *$ & 42.0414 & $* * *$ \\
\hline & $(3.4763)$ & & $(3.7051)$ & \\
\hline IPW & 26.1319 & $* * *$ & 39.8239 & $* * *$ \\
\hline & $(2.1881)$ & & $(2.2728)$ & \\
\hline DR & 30.6167 & $* * *$ & 46.7407 & $* * *$ \\
\hline & $(2.3509)$ & & $(2.6741)$ & \\
\hline SIP vs. Private Voucher Schools & & & \\
\hline OLS & 21.6433 & $* * *$ & 34.9510 & $* * *$ \\
\hline & $(3.5009)$ & & $(2.7611)$ & \\
\hline Matching & 23.4026 & $* * *$ & 37.7115 & $* * *$ \\
\hline & $(4.7003)$ & & $(4.5890)$ & \\
\hline IPW & 20.7623 & $* * *$ & 34.2366 & $* * *$ \\
\hline & $(3.1007)$ & & $(3.1620)$ & \\
\hline DR & 13.6527 & $* *$ & 24.1578 & $* * *$ \\
\hline & $(3.0748)$ & & $(3.3754)$ & \\
\hline
\end{tabular}

\begin{tabular}{|l|c|c|c|c|}
\hline SIP vs. Private Non Voucher Schools & & & \\
\hline OLS & 15.052 & $* * *$ & 26.1601 & $* * *$ \\
\hline & $(3.838)$ & & $(4.1964)$ & \\
\hline Matching & 17.1732 & $* * *$ & 28.2399 & $* * *$ \\
\hline & $(3.2302)$ & & $(3.1980)$ & \\
\hline IPW & 14.205 & $* * *$ & 25.4186 & $* * *$ \\
\hline & $(2.995)$ & & $(3.0198)$ & \\
\hline DR & 16.2137 & $* * *$ & 26.7779 & $* * *$ \\
\hline & $(2.8052)$ & & $(2.8698)$ & \\
\hline
\end{tabular}

Notes: Standard errors in parentheses. $* * *$ denotes significance at the $1 \%$ level. 